\title{
A Survey of Campylobacter jejuni Contamination in Modern Broiler Production and Processing Systems
}

\author{
F.T. JONES'•, R.C. AXTELL ${ }^{2}$, D.V. RIVES', S.E. SCHEIDELER', F.R. TARVER, JR. ${ }^{3}$, \\ R.L. WALKER ${ }^{4}$, and M.J. WINELAND' \\ 'Department of Poultry Science; ${ }^{2}$ Department of Entomology; ${ }^{3}$ Professor Emeritus, Department of Food Science; North Carolina State University, \\ Raleigh, North Carolina 27695, and ${ }^{4}$ California Veterinary Diagnostic Laboratory, School of Veterinary Medicine. \\ University of California, Davis, California 95616
}

(Received for publication July 6,1990)

\begin{abstract}
Campylobacter jejuni contamination was surveyed in samples collected from the breeder-multiplier houses, broiler houses, feed mills, hatcheries, and processing plants of two integrated broiler firms. Insects and mice were also trapped at each location. $C$. jejuni was most frequently found in samples collected from processing plants, followed by samples collected from broiler houses, and breeder-multiplier houses. Samples obtained from feed mills and hatcheries were negative, suggesting that the $C$. jejuni was not transmitted by either feed or eggs. C. jejuni was also not isolated from insect or mouse samples. However, the external surfaces of insects were sanitized with a chlorine solution, prior to analysis. Thus, these data suggest any contamination of insects with $C$. jejuni is generally external not internal. Contamination in broilers apparently originated from some unknown source(s) in broiler houses. C. jejuni was isolated from $20 \%$ of the cloacal swabs taken as birds entered the plant, $52 \%$ of the carcasses sampled following immersion chilling, and $31.6 \%$ of whole broiler carcasses sampled at retail outlets. While these data suggest that crosscontamination occurred within processing plants, field control methods would appear to be necessary for control of $C$. jejuni in modern broiler production and processing systems. The frequent C. jejuni isolations from dead birds in broiler houses suggested the regular collection of normal mortality as one farm management procedure that might help reduce Campylobacter contamination in broilers.
\end{abstract}

Campylobacter jejuni is the most common cause of acute bacterial gastroenteritis in humans in the United States (2). In fact, Campylobacter infection rates in the United States exceed the combined infection rates of Salmonella and Shigella (34). Campylobacter infections have often been linked with the consumption of chicken, particularly raw or undercooked chicken $(11,27)$. Garcia $(15)$, who recently published a brief review of Campylobacter infection in humans, has summarized the importance of the organism by terming the organism "the next Salmonella."

While several researchers have isolated Campylobacter from processed poultry $(3,11,16,18,28,33)$, the epidemiology of the pathogen in poultry production and processing is poorly understood. In a survey of Campylobacter contamination on chicken farms, Smitherman et al. (31) re-

*Author to whom correspondence should be addressed. ported that the organism could not be isolated from certain broiler houses, but all birds become positive within a week after the first isolation of the organism within a given house. These researchers also reported that feed, litter, and water samples became contaminated only after Campylobacter was isolated from live birds. Genigeorgis et al. (16) confirmed that feed, water, and litter were negative for Campylobacter prior to infection of live birds, but suggested that contamination might be spread from an infected flock of birds to succeeding flocks via litter.

Genigeorgis et al. (16) also surveyed Campylobacter contamination during processing and reported that poor sanitation in scalding tanks and defeathering machines increased cross-contamination rates. Baker et al. (3) confirmed that cross-contamination does occur during scalding and defeathering, but noted that the evisceration stage is probably more important with respect to cross-contamination than are either scald or defeathering. These researchers observed that the number of $C$. jejuni on carcasses decreases following washing and chilling. Izat et al. (18) confirmed the effect of chilling on $C$. jejuni numbers. Both studies $(3,18)$ suggest that cross-contamination in the processing plant is virtually impossible to eliminate. Thus, the production of poultry products which are free of $C$. jejuni contamination depends upon whether or not live birds contain the organism prior to processing.

In view of this situation, this project was undertaken to estimate $C$. jejuni contamination rates at various points in the broiler production and processing system in order to gain a more thorough understanding of the epidemiology of the organism.

\section{MATERIALS AND METHODS}

\section{Sampling methods}

The two integrated broiler firms which cooperated with this study followed standard industry practices, but neither firm had an active microbial control program. Samples were collected from each company on 3 separate days 2 weeks apart. Samples were collected from two different breeder-multiplier houses, two different broiler houses, the feed mill, the hatchery, and the processing plant on each sampling day. Insects and mice were trapped at each location and transported to the laboratory for analysis. To ensure 
that any contamination detected was internal, the external surfaces of insects were sanitized. Insects were rinsed in sterile distilled water, sanitized with $20 \mathrm{ppm}$ chlorine solution, and rinsed three times in sterile distilled water before being placed into media for analysis. Captured mice were killed using carbon dioxide, wet thoroughly with $95 \%$ ethanol, aseptically opened with sterile scissors, and the entire gastrointestinal tract was aseptically removed. The tract was then cut in 6 to 10 pieces before being placed in media for incubation.

In breeder-multiplier houses, subsamples of feed, floor litter, and nest litter were collected from five separate locations within each house using sterile tablespoons. Composite samples were made by combining the five subsamples and mixing thoroughly in a sterile, aluminum roasting pan. About $25 \mathrm{~g}$ of the material was then transferred directly into the enrichment medium for incubation. Egg rinses were done using the method of Gentry and Quarles (17).

Samples collected in broiler houses were from those houses which contained birds which were 6 to 7 weeks of age. In broiler houses composite samples of feed and litter were collected as in breeder-multiplier houses. Water samples were collected by using a sterile tablespoon. About $5 \mathrm{ml}$ of water was collected from five separate watering devices and placed into the enrichment medium. Live bird and dead bird rinses were done using the method described by Cox et al. (10). Environmental swabs were collected by wetting a sterile cotton-tipped swab (Fisher Scientific, Pittsburgh, PA) with enrichment medium and rubbing it over an area of about 930 sq. $\mathrm{cm}$. before returning it to the medium for incubation. A pair of disposable latex gloves was worn during the collection of environmental swabs with a new pair being used to collect each sample.

Grab samples of feed ingredients (ca. $500 \mathrm{~g}$ ) were collected in the feed mill at the batch scales, while grab samples of finished feeds (ca. $500 \mathrm{~g}$ ) were collected from pellet coolers and during loading of feed delivery trucks. Environmental swabs were collected in the feed mill as described above.

In hatcheries, samples of yolk sac material were collected from day-old chicks, following cervical dislocation, by thoroughly wetting abdomen of the chick with $95 \%$ ethanol, aseptically opening the chick with sterile scissors and excising about a 1-g portion of yolk material. Yolk sac materials from six chicks were combined to form one composite sample. Samples of Marek's disease vaccine were collected by allowing the vaccinating apparatus to deliver one dose of vaccine directly into the enrichment medium for incubation. Environmental swabs were collected as described from hatchers and chick boxes except $6.5 \mathrm{sq}$. $\mathrm{cm}$. was rubbed.

Three subsamples of debris were collected from shipment coops at the processing plant using sterile tablespoons. Subsamples were combined to form composite samples, of which three to seven were collected on each sampling day. Cloacal swab was collected from individual birds just prior to kill. Swabs from five individual birds were combined to form composite samples, and four composite samples were collected on each sampling day. Carcass rinse samples were collected on individual birds at the immersion chiller exit and just prior to packaging. Rinses were done using the method described by Cox et al. (10).

One case of whole bird carcasses $(31.8 \mathrm{~kg})$ from each of four different broiler companies was purchased at a retail outlet. Carcasses were transported to the laboratory, where each carcass was rinsed using the method of Cox et al. (10) and analyzed for Campylobacter using the laboratory procedures outlined below.

\section{Laboratory procedures}

Samples of approximately $25 \mathrm{~g}$ were collected directly into $225 \mathrm{ml}$ of semisolid Preston's broth $[25 \mathrm{~g} / \mathrm{L}$ nutrient broth \#2 (Oxoid USA, Columbia, MD), $50 \mathrm{ml} / \mathrm{L}$ lysed horse blood (EDI,
Burlington, NC), $5000 \mathrm{IU} / \mathrm{L}$ polymyxin B (Sigma, St. Louis, MO), $0.01 \mathrm{~g} / \mathrm{L}$ rifampicin (Sigma), $0.01 \mathrm{~g} / \mathrm{L}$ trimethoprim lactate (Sigma), 0.1 g/L cyclohexamide (Sigma), $1.6 \mathrm{~g} / \mathrm{L}$ agar (Difco, Detroit, MI)], while swab samples were placed in $10 \mathrm{ml}$ of semisolid Preston's broth. Both samples and swabs were incubated at $42^{\circ} \mathrm{C}$ for $48 \mathrm{~h}$. A loop of enrichment broth was then streaked on Skirrow's (BBL, Cockeysville, MD) and Campy-BAP (BBL) agars for isolation. Isolation media were incubated at $42^{\circ} \mathrm{C}$ for $48 \mathrm{~h}$ in anaerobic jars equipped with Campy Paks (BBL). Suspect colonies were picked to Brucella broth (Difco) containing $0.16 \%$ agar (Difco) and incubated in anaerobic jars equipped with Campy Paks (BBL) for $24 \mathrm{~h}$. A wet mount preparation of each isolate was examined under a phase-contrast microscope for characteristic morphology $(0.2$ to $0.8 \mu \mathrm{m}$ by 1.5 to $5 \mu \mathrm{m}$ curved rods) and corkscrew-like motility. Isolates with characteristic morphology and motility were tested for oxidase, catalase, and ability to hydrolyze hippurate using methods described by Park et al. (26). Isolates with characteristic morphology and motility which were oxidase, catalase, and hippurate positive were classified as C. jejuni.

\section{RESULTS AND DISCUSSION}

Table 1 contains an overview of the results obtained from the survey of broiler production and processing systems for $C$. jejuni contamination. The highest percentage of samples contaminated with $C$. jejuni were those obtained from processing plants $(31.6 \%)$, followed by those obtained from broiler houses $(5.0 \%)$ and breeder-multiplier houses $(3.9 \%)$. C. jejuni was not isolated from samples obtained from feed mills or hatcheries.

The failure to isolate $C$. jejuni from samples collected at feed mills agrees with the data of Smitherman et al. (31) and Genigeorgis et al. (16). Both studies failed to isolate Campylobacter from feed at the farm level. Furthermore, since Campylobacter survives poorly when: a) Desiccated $(14)$, b) Exposed to air (6), or c) Stored for several days at $25^{\circ} \mathrm{C}(13)$, these data were not surprising.

The failure to isolate $C$. jejuni from samples collected at hatcheries is analogous to findings reported by Baker et al. (3) and Izat and Gardner (19), neither of whom isolated Campylobacter from commercial eggs. Acuff et al. (1) showed in turkeys and Doyle (12) in chickens that $C$. jejuni is not likely to contaminate the contents of uncracked eggs. However, Clark and Bueschkens ( 8 ) found that $C$. jejuni could be isolated from up to $10 \%$ of the day-old chicks hatched from artificially contaminated hatching eggs. These researchers also suggested that no one has examined a significant number of newly hatched chicks to determine if egg contamination is a route of transmission in the field situations. The fact that $C$. jejuni was not isolated from the composite day-old chick samples (which represented a total

TABLE 1. Campylobacter jejuni isolation from various sampling points in broiler production and processing systems.

\begin{tabular}{lccc}
\hline Sampling & $\begin{array}{c}\text { No. samples } \\
\text { collected }\end{array}$ & \multicolumn{2}{c}{ Positive samples } \\
\cline { 2 - 4 } location & 77 & 3 & No. \\
\hline Breeder-multiplier house & 120 & 7 & 3.9 \\
Broiler house & 78 & 0 & 5.8 \\
Feed mill & 106 & 0 & 0.0 \\
Hatchery & 95 & 31 & 0.0 \\
Processing plant & 98 & 31 & 32.6 \\
Retail carcasses & & & 31.6 \\
\hline
\end{tabular}


of 228 chicks) collected in this study, suggests that eggs were not the route by which $C$. jejuni was transmitted in this study.

Insect samples were collected from all five sampling locations listed in Table 1. The insect samples included a total of 58 Alphatobius spp. (lesser meal worm), 14 Periplaneta americana (American cockroach) samples, 8 Blatella germanica (German cockroach) samples, 8 Carcinops pumuilo (carcinops beetle) samples, 4 Phaenicia sericata (blow fly) samples, 4 Alphatobius diaperinuns (darkling beetle) samples, 2 Musca domestica (house fly) samples, and 2 Tribolium confusum (confused flour beetle) samples. To ensure that any contamination detected was internal, the external surfaces of insects were sanitized with a chlorine solution. Since $C$. jejuni was not isolated from any of these samples (data not shown), these data suggest that if insects were contaminated, it was external not internal. Thus, insects apparently carried any contamination on their external surfaces. The prevalence of $C$. jejuni is high in flies captured on chicken farms (27), and Shane et al. (29) demonstrated that under laboratory conditions house flies can transmit $C$. jejuni to chickens. However, Shane et al. (29) tested flies within $2 \mathrm{~h}$ of exposure to $10^{8} \mathrm{C}$. jejuni and did not attempt to determine how long contamination persisted within exposed flies. In addition, neither study sanitized the external surfaces of insects prior to analysis $(27,29)$.

Mice were trapped in each of the sampling locations listed in Table 1. The mouse samples collected were negative for $C$. jejuni. Since $C$. jejuni has been isolated from small rodents (24), this result was unexpected.

In breeder-multiplier houses (Table 2), C. jejuni was isolated from the shells of 2 of 11 floor egg samples and from 1 of 17 nest litter samples. C. jejuni was not isolated from floor litter, nest egg, or feed samples. The low isolation rates from nest litter suggests that perhaps the $C$.

TABLE 2. Campylobacter isolation from the breeder-multiplier house environment.

\begin{tabular}{lccr}
\hline Sample type & $\begin{array}{c}\text { No. samples } \\
\text { collected }\end{array}$ & \multicolumn{2}{c}{ Positive samples } \\
\cline { 3 - 4 } & 10 & 0 & No. \\
\hline Feed & 11 & 2 & 0.0 \\
Floor egg rinse & 19 & 0 & 18.2 \\
Floor litter & 20 & 0 & 0.0 \\
Nest egg rinse & 17 & 1 & 0.0 \\
Nest litter & 77 & 3 & 5.9 \\
All samples & & & 3.9 \\
\hline
\end{tabular}

TABLE 3. Campylobacter jejuni isolation from the broiler house environment.

\begin{tabular}{lccc}
\hline Sample type & $\begin{array}{c}\text { No. samples } \\
\text { collected }\end{array}$ & \multicolumn{2}{c}{ Positive samples } \\
\cline { 3 - 4 } & 10 & 0 & No. \\
\hline Feed & 10 & 0 & 0.0 \\
Litter & 10 & 0 & 0.0 \\
Water & 10 & 4 & 0.0 \\
Dead bird rinse & 10 & 0 & 40.0 \\
Live bird rinse & 40 & 3 & 0.0 \\
Feces & 30 & 0 & 7.5 \\
Environment & 120 & 7 & 0.0 \\
All samples & & & 5.8 \\
\hline
\end{tabular}

jejuni contamination of nest litter was transitory and due to fecal contamination. The isolation of $C$. jejuni from nest litter and floor egg samples suggests that every hatching egg could be exposed to Campylobacter. However, egg transmission did not appear to be the primary means by which C. jejuni was transmitted. Indeed, Clark and Bueschkens (9) found that when $10^{6}$ Campylobacter organisms were introduced into egg albumen, they could not be reisolated after $24 \mathrm{~h}$.

The data in Table 3 were collected from apparently normal broiler flocks which were experiencing no excessive mortality. North (23) reported that $5 \%$ of the birds started as chicks will die before processing on normal broiler farms. Zander (36) reported that in the absence of excessive mortality, dead are collected for disposal, but no cause of death is determined. Thus, no cause of death was obtained for the dead birds sampled in this study. Nonetheless, several studies $(4,30)$ have indicated that $C$. jejuni colonizes the intestinal tract of broilers without causing pathology to internal organs or the intestinal tract. Therefore, it would appear unlikely that $C$. jejuni caused the death of the birds sampled. C. jejuni was found in 4 of the 10 dead bird samples collected. The low isolation rate $(3 / 40)$ from the droppings samples collected probably reflects the fragile nature of the organism. Indeed, Leuchtefeld et al. (21) demonstrated that $C$. jejuni could not be isolated from turkey feces $24 \mathrm{~h}$ after placing the material on filter paper. The isolation rate reported here $(7.5 \%)$ is about half of that reported by Smitherman et al. (31) (14.5\%). It has also been demonstrated that fecal isolation rates in apparently normal flocks can range from 0 to $100 \%$ of samples positive for Campylobacter, depending on the flock (31). The failure to isolate $C$. jejuni from feed collected in broiler houses is consistent with the data obtained from samples collected in feedmills. The failure to isolate $C$. jejuni from litter and water was somewhat surprising since other researchers have suggested that these may be vehicles by which Campylobacter spreads within broiler flocks $(16,22)$. Nevertheless, the frequency of $C$. jejuni isolation from dead bird samples suggests that caretakers might minimize the spread of Campylobacter within broiler flocks by the regular collection of dead birds.

In processing plants (Table 4$), C$. jejuni was not isolated from samples collected from live haul trucks, but $20 \%$ of the cloacal swabs taken as birds entered the plant and $52 \%$ of the processed broiler carcasses sampled following immersion chilling were positive. The $52 \%$ contamination rate reported here is $5.5 \%$ higher than the $46.5 \%$ reported by other researchers (28). Lillard (20) showed that the number of bacteria decreased as carcasses moved through the processing plant, but the number of Salmonella positive carcasses increased significantly following immersion

TABLE 4. Campylobacter isolation from broiler processing plants.

\begin{tabular}{lccr}
\hline Sample type & $\begin{array}{c}\text { No. samples } \\
\text { collected }\end{array}$ & \multicolumn{2}{c}{ Positive samples } \\
\cline { 2 - 4 } & 20 & No. & $\%$ \\
\hline Debris in shipment coops & 25 & 5 & 0.0 \\
Cloacal swabs at kill & 50 & 26 & 20.0 \\
Carcasses after chill & 95 & 31 & 32.0 \\
All samples &
\end{tabular}


chilling. Baker et al. (3) and Izat et al. (18) showed that the number of $C$. jejuni organisms also decreased steadily as birds proceed through the processing plant. Nonetheless, the data in Table 4 suggest that while $C$. jejuni numbers may be decreasing, cross-contamination appears to occur during processing.

The data in Table 5 show that $C$. jejuni was isolated from about $31.5 \%$ of the whole broiler carcasses sampled at retail outlets. These data suggest that there was little difference between broilers of the various companies sampled with respect to the number of carcasses contaminated with Campylobacter. Indeed, when a chi square analysis was performed by hand using the formulas of Snedecor and Cochran (32) for the calculations, the number of positive carcasses was the same $(\mathrm{P}<.01)$. The percentage of con-

TABLE 5. Campylobacter isolation from retail purchased broiler carcasses.

\begin{tabular}{cccc}
\hline \multirow{2}{*}{ Company } & $\begin{array}{c}\text { No. of } \\
\text { samples }\end{array}$ & \multicolumn{2}{c}{ Positive samples } \\
\cline { 3 - 4 } & 24 & 9 & No. \\
2 & 24 & 8 & 37.5 \\
3 & 28 & 8 & 33.3 \\
4 & 22 & 6 & 28.6 \\
All samples & 98 & 31 & 31.6 \\
\hline
\end{tabular}

taminated retail carcasses reported here $(31.5 \%)$ is $1.75 \%$ higher than that reported by Stern et al. (33) (29.75\%) and is $9.5 \%$ higher than that reported by Seattle-King County Department of Public Health (28) (22.3\%).

Campylobacter has been isolated from numerous animals $(5,22,25,35)$ as well as from river water $(7)$, but these contamination sources have yet to be linked to contamination of broilers. Further research is needed to determine the primary source(s) from which Campylobacter originates and to design methods to control contamination from these sources.

In summary, the data presented herein suggest the following conclusions: a) $C$. jejuni did not appear to be transmitted by either feed or eggs; b) $C$. jejuni was present in the breeder-multiplier house environments; c) $C$. jejuni contamination in broilers apparently originated from some unknown source(s) in broiler houses; and d) $C$. jejuni could be isolated from $20 \%$ of the cloacal swabs taken as birds entered the plant, $52 \%$ of the processed broiler carcasses sampled following immersion chilling, and $31.6 \%$ of whole broiler carcasses sampled at retail outlets. While crosscontamination appeared to occur within processing plants, field control methods for $C$. jejuni would appear to be required to control this pathogen in broilers. The frequency of C. jejuni isolation from dead bird samples suggests that caretakers might minimize the spread of Campylobacter within broiler flocks by the regular collection of dead birds within the broiler house environment.

\section{ACKNOWLEDGMENTS}

The technical assistance of Mr. Timothy Hurley and Mr. George Gartrell is greatly appreciated. The authors are also grateful to Dr. Nancy Hunter and Ms. Linda Star, of the North Carolina State Public Health Laboratory, for their assistance in media preparation. This work was supported by Southeastern Poultry and Egg Association Grant \#M2. The authors gratefully acknowledge the support.

\section{REFERENCES}

1. Acuff, G.R., C. Vanderzant, F.A. Gardner, and F.A. Golan. 1982. Examination of turkey eggs, poults and brooder house facilities for Campylobacter jejuni. J. Food Prot. 45:1279-1281.

2. Archer, D.L., and F.E. Young. 1988. Contemporary issues: Diseases with a food vector. Clin. Microbiol. Rev. 1:377-398.

3. Baker, R.C., M.D.C. Paredes, and R.Q. Qureshi. 1987. Prevalence of Campylobacter jejuni in eggs and poultry meat in New York State. Poultry Sci. 66:1766-1770.

4. Beery, J.T., M.B. Hugdahl, and M.P. Doyle. 1988. Colonization of gastrointestinal tracts of chicks by Campylobacter jejuni. Appl. Environ. Microbiol. 54:2365-2370.

5. Blazer, M.J., F.M. LaForce, N.A. Wilson, and W.L. L Wang. 1980. Reservoirs for human campylobacteriosis. J. Infect. Dis. 141:665-669.

6. Bolton, F.J., D. Coates, and D. N. Hutchinson. 1984. The ability of Camplobacter media supplement to neutralize photochemically induced toxicity and hydrogen peroxide. J. Appl. Bacteriol. 56:151-157.

7. Bolton, F.J., D. Coates, D.N. Hutchinson, and A.F. Godfree. 1987. A study of thermophilic campylobacters in a river system. J. Appl. Bacteriol. 62:167-176.

8. Clark, A.G., and D.H. Bueschkens. 1986. Effect of egg storage upon the survival of Campylobacter jejuni in laboratory-infected fertile poultry eggs. Avian Dis. 30:76-80.

9. Clark, A.G., and D.H. Bueschkens. 1986. Survival and growth of Campylobacter jejuni in egg yolk and albumen. J. Food Prot. 49:135141.

10. Cox, N.A., J.E. Thompson, and J.S. Bailey. 1983. Procedure for isolation and identification of Salmonella from poultry carcasses. U.S. Dept. of Agr., Agr. Res. Serv. Handbook No. 603.

11. Deming, M.S., R.V. Tauxe, P.A. Blake, S.E. Dixon. B.S. Fowler, T.S. Jones, E.A. Lockamy, C.M. Patton, and R.O. Sikes. 1987. Campylobacter enteritis at a university: transmission from eating chicken and from cats. Am. J. Epidemiol. 126:526-534.

12. Doyle, M.P. 1984. Association of Campylobacter jejuni with laying hens and eggs. Appl. Environ. Microbiol. 47:533-536.

13. Doyle, M.P., and D.J. Roman. 1981. Growth and survival of Campylobacter fetus subsp. jejuni as a function temperature and $\mathrm{pH}$. J. Food Prot. 44:496-601.

14. Doyle, M.P., and D.J. Roman 1982. Sensitivity of Campylobacter jejuni to drying. J. Food Prot. 45:507-510.

15. Garcia, M.M. 1990. Campylobacter: The next Salmonella. Safety Watch Foodborne Dis. Bull., Agriculture Canada, Food Production and Inspection Branch, Ottawa, Canada No. 15. pp. 1-2.

16. Genigeorgis, C., M. Hassuneh, and P. Collins. 1986. Campylobacter jejuni infection on poultry farms and its effect on poultry meat contamination during slaughter. J. Food Prot. 49:895-903.

17. Gentry, R.F., and C.L. Quarles. 1967. The measurement of bacterial contamination on egg shells. Poultry Sci. 46:1263.

18. Izat, A.L., F.A. Gardner, J.H. Denton, and F.A. Golan. 1988. Incidence and level of Campylobacter jejuni in broiler processing. Poultry Sci. 67:1568-1572.

19. Izat, A.L., and F.A. Gardner. 1988. Incidence of Campylobacter jejuni in processed egg products. Poultry Sci. 67:1431-1435.

20. Lillard, H.S. 1990. The impact of commercial processing procedures on the bacterial contamination and cross-contamination of broiler carcasses. J. Food. Prot. 53:202-204.

21. Luechtefeld. N.W., W.L.L. Wang, and M.J. Blaser. 1981. Evaluation of transport and storage techniques for isolation of Campylobacter fetus and jejuni from turkey fecal samples. J. Clin. Microbiol. 13:438-443.

22. Montrose, M.S., S.M. Shane, and K.S. Harrington. 1985. Role of litter in the transmission of Campylobacter jejuni. Avian Dis. 29:392-399.

23. North, M.O. 1978. Commercial chicken production manual, 2 nd ed. AVI Publishing Co. Inc., Westport, CT. p. 375.

24. Pacha, R.E., G.W. Clark, E.A. Williams, A.M. Carter, J.J. Scheffelmaier, and P. Debusschere. 1987. Small rodents and other mammals associated with mountain meadows as reservoirs of Giardia spp. and Campylobacter spp. Appl. Environ. Microbiol. 53:15741579.

25. Pacha, R.E., G.W. Clark, E.A. Williams, and A.M. Carter. 1988. Migratory birds of central Washington as reservoirs of Campylobacter jejuni. Can. J. Microbiol. 34:80-82.

26. Park, C.E., R.M. Smibert, M.J. Blazer, C. Vanderzant, and N.J. Stern. 1984. Campylobacter. pp 386-404. In M. Speck (ed.), Compendium of methods for the microbiological examination of foods, 2 nd ed. Ameri- 
can Public Health Association, Washington, DC.

27. Rosef, O., and G. Kapperud. 1983. House flies (Musca domestica) as possible vectors of Campylobacter fetus subsp. jejuni. Appl. Environ. Microbiol. 45:381-383.

28. Seattle - King County Department of Public Health. 1984. Surveillance of the flow of Salmonella and Campylobacter in a community. Contract \#223817041. Report to U.S. Food and Drug Administration. Seattle - King County Department of Public Health, Seattle, WA.

29. Shane, S.M., M.S. Montrose, and K.S. Harrington. 1985. Transmission of Campylobacter jejuni by the housefly (Musca domestica). Avian Dis. 29:384-391.

30. Shanker, S., A. Lee, and T.C. Sorrell. 1988. Experimental colonization of broiler chicks with Campylobacter jejuni. Epidemiol. Infect. 100:27-34

31. Smitherman, R.E., C.A. Genigeorgis, and T.B. Farver. 1984. Preliminary observations on the occurrence of Campylobacter jejuni at four California chicken ranches. J. Food Prot. 47:293-298.
32. Snedecor, G.W., and W.G. Cochran. 1967. Statistical methods, 6th ed. Iowa State University Press, Ames, IA. pp. 20-21.

33. Stern, N.J., M.P. Hernandez, L. Blankenship, K.E. Deibel, S. Doores, M.P. Doyle, H. Ng, M.D. Pierson, J.N. Sofos, W.H. Sueum, and D.C. Westoff. 1985. Prevalence and distribution of Campylobacter jejuni and Campylobacter coli in retail meats J. Food Prot. 48:595-599.

34. Stern, N.J., and S.U. Kazmi. 1989. Campylobacter jejuni. pp. 71-110. In M.P. Doyle (ed.), Foodborne bacterial pathogens. Marcel Dekker, Inc., New York.

35. Whelan, C.D., P. Monaghan, R.W.A. Girdwood, and C.R. Fricker. 1988. The significance of wild birds (Larus spp.) in the epidemiology of Campylobacter infection in humans. Epidemiol. Infect. 101:259267.

36. Zander, D.V. 1984. Principles of disease prevention: Diagnosis and control. pp. 1-37. In M.S. Hofstad (ed.), Diseases of poultry, 8th ed. Iowa State University Press, Ames, IA. 